\title{
A Comparative Study of Disposable Agriculture Coveralls Based on Wearer Trials
}

\author{
Yanmei Li, Charlotte Coffman, Susan Ashdown* and Jintu Fan* \\ Department of Fiber Science \& Apparel Design, College of Human Ecology, Cornell University, USA
}

Submission: September 13, 2017; Published: October 04, 2017

*Corresponding author: Susan Ashdown and Jintu Fan, Department of Fiber Science \& Apparel Design, College of Human Ecology, Cornell University, USA, Email: spa4@cornell.edu; jf456@cornell.edu

\begin{abstract}
Agricultural workers require work wear that fits well and is comfortable, durable, and protects from hazardous substances encountered in the work place. In order to understand how garment style and design details affect fitting, mobility, durability and protection, three styles of disposable agricultural coveralls are compared through wearer trials. They include a traditional disposable coverall from the market (Labeled as "B"), a modified coverall from the same manufacturer with elastic panels in the back (Labeled as " $\mathrm{R}$ ") and a design created by the researchers that incorporates pleated sections (Labeled as “P). By analyzing the data of the wearer trials and wearers' feedbacks, it was found that the pleat design in " $\mathrm{P}$ " style was the least preferred in terms of fitting as the pleats were opened in stretch movements and present a hindrance due to the fact that they did not lay flat. Instead, users preferred the "R" style as the elastic panels under the arms and at back provides adjustability for fitting. The "R" style also showed the least tear damage in high tear risk areas (i.e. torso, ankle and lower leg), while the "p" style has the higher tear risk in most of sections except the sleeve section. In terms of abrasion resistance, the "B" style is most preferred, followed by the " $\mathrm{R}$ " and "P" style. No significant differences were found among the three styles in terms of dirt resistance. While " $\mathrm{R}$ " style was the most preferred, future improvement can be made by adding pockets, using larger zipper pulls, removing ankle elastic and adding leg opening zippers, and making adjustable fit at different areas of the body. By analyzing the data of the wearer trials and wearers' feedbacks, in terms of fitting, it was found that the pleat design in " $\mathrm{P}$ " style was the least preferred as the pleats were opened in stretch movement, but were perceived as a hindrance due to the fact that the pleats did not lie flat..Instead, users preferred the " $R$ " style for adjustability. In terms of tear resistance, the " $R$ " style is again preferred, showing least tear damage in high tear risk areas (i.e. torso, ankle and lower leg), while the "p" style has the higher tear risk in most of sections except sleeve section. In terms of abrasion resistance, the "B" style is most preferred, followed by the " $\mathrm{R}$ " and " $\mathrm{P}$ " style. No significant differences were found among the three styles in terms of dirt resistance.
\end{abstract}

Keywords: Coverall prototype; Agricultural worker; Garment design; Wearer trial

\section{Introduction}

Agricultural workers require protective coveralls with good fit, comfort and durability, which can keep them clean and safe from dirt, stain, and harmful contaminants, at an economical price. Many researchers have studied the fitting, comfort and durability of protective coveralls from different perspectives. Crow \& Dewar [1] used rubber sheeting with horizontal and vertical slits to determine areas of stress in combat coveralls to determine minimum seam strength requirements. Airey [2] discussed the requirements of agriculture coveralls and proposed a range of garments suitable for agriculture applications. Ashdown \& Watkins [3] focused on the development of a mobility analysis test and applied it for investigating the mobility issues of disposable coveralls. Huck et al. [4,5] studied the effects of adding ease at a specific area of a garment on a range of motion measures and subjective perceptions of fit comfort and mobility. They particularly examined alternative coverall designs of added crotch ease. Boorady et al [6] investigated restrictions in mobility, problems with tears and issues regarding wearing practices and donning when pesticide applicators wearing coveralls with their equipment under varying working positions. Based on the requirements of functional garments, Boorady [7] discussed the concept of "functional ease", which is essential for functional garments to be adaptable to the movement of the wearer while maintaining its purpose. Jeon \& Moon [8] studied the size specifications and consistency as well as the regularity and fitness of disposal protective coveralls available to Korean agricultural workers.

There have also been considerable studies focused on the thermal comfort of protective coveralls [9-14]. Both the properties of fabric materials and garment styles were considered in these investigations.

Although considerable work has been carried out in the past, findings vary greatly due to the subjectivity in wearer trials 
and variations in actual working environments. Today, many different types of agricultural coveralls are available in market, but their performance in terms of fit, durability and protection have not been systematically evaluated from the end users' prospective, and hence presents real problems in the selection and further development of such agricultural cover all. In order to better understand how some of the typical designs of agricultural coveralls perform in actual use conditions and how their performance relates to design and construction, in this study, we compared the performance of three typical styles-one traditional coverall and two modified coveralls that followed the results or suggestions of earlier researchers and added an elastic area or extensible area to improve mobility. 49 agricultural workers in four states participated in the wear trails. The trial logs and questionnaires about final evaluations of the coveralls were analyzed.

\section{Garment samples}

Three styles of agricultural coveralls are compared in this study. The first one is the traditional disposable coverall available on the market shown in (Figure 1). It has an attached hood, front zipper closure, and elastic at waist, wrists and ankle.

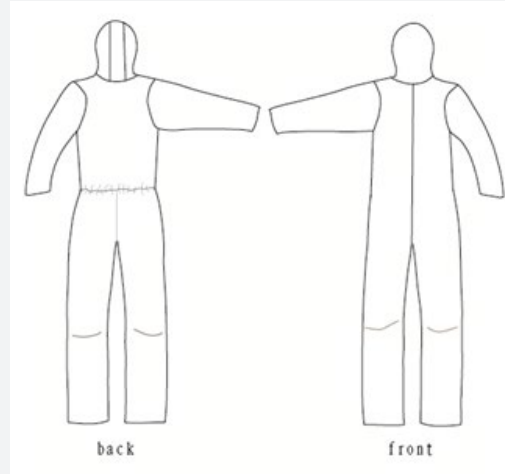

Figure 1: Traditional coverall (labeled as "B").

Table 1: Properties of the Fabrics for the Three Coverall Styles.

\begin{tabular}{|c|c|c|c|c|c|c|c|c|c|c|c|c|c|}
\hline \multirow{2}{*}{ Fabrics } & \multirow{2}{*}{$\begin{array}{l}\text { Weight } \\
\left(\mathrm{g} / \mathrm{m}^{2}\right)\end{array}$} & \multirow[t]{2}{*}{$\begin{array}{c}\text { Thickness } \\
\text { (mm) }\end{array}$} & \multicolumn{3}{|c|}{ Bending Rigidity $(\mu N \cdot m)$} & \multicolumn{3}{|c|}{ tensile strength $(\mathrm{N})$} & \multicolumn{3}{|c|}{ tensile extension (\%) } & \multicolumn{2}{|c|}{ tear strength $(\mathrm{N})$} \\
\hline & & & wrap & weft & diagonal & warp & weft & diagonal & warp & weft & diagonal & warp & weft \\
\hline$B \& R$ & 121 & 0.47 & 1.21 & 1.63 & 1.25 & 121.98 & 48.14 & 66.93 & 55.31 & 56.81 & 45.89 & 19.16 & 42.90 \\
\hline$P$ & 123 & 0.33 & 0.97 & 1.04 & 0.62 & 113.10 & 34.87 & 62.19 & 79.34 & 102.39 & 85.33 & 28.80 & 76.57 \\
\hline
\end{tabular}

Covers all in these three styles were made in five different sizes ranging from Small to XX Large based on Size USA data. The "B" and "R" styles were made of the Klee guard fabric and the "P" style was made of proshield fabric, both from DuPont. Their mass per unit area were determined by weighing fabric samples of specific area, and their thickness (under 0.196N/ $\mathrm{mm}^{2}$ ) and bending rigidity were tested using the Siro FAST

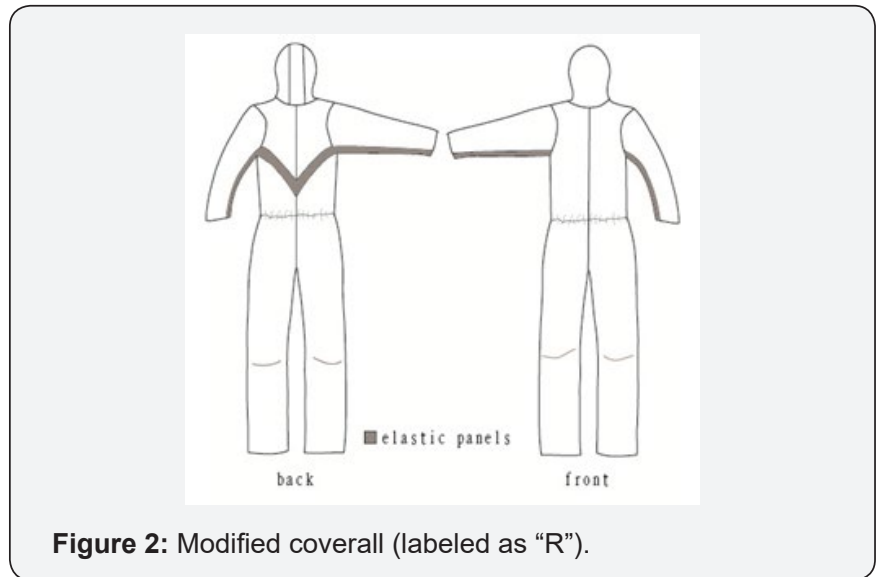

The second style is modified from the traditional coverall. As shown in (Figure 2), it has elastic panels added to the traditional style in the underarm and back area. The third style is the newly developed pleat design, labeled as "P" in this study. The new design, shown in (Figure 3), has pleats covering the underarm, buttock, and knee areas. The pleats are intended to provide mobility.

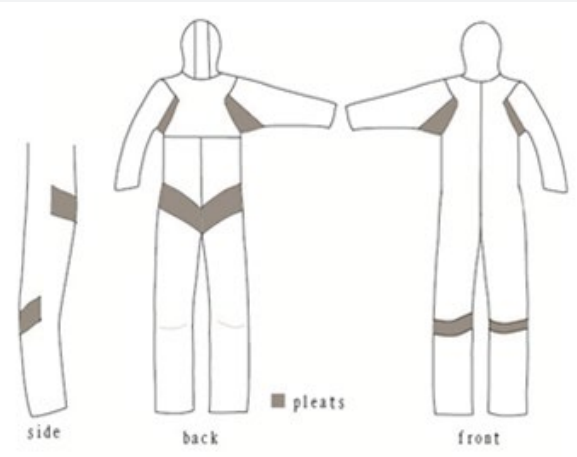

Figure 3: New pleat design (labeled as "P").

(Fabric Assurance by Simple Tests) system and listed in (Table 1). As can be seen, the fabric for "P" style is thinner and softer. The tensile and tear strength of fabrics were tested by Instron universal material testing machine. Although the tensile strength of fabric for "P" style is a slightly less than that of the fabric for "B \& $\mathrm{P}$ " style, its tear strength is much greater. 
The abrasion resistances of the two fabrics were tested using the Martindale abrasion tester according to ASTM D4966. (Figure 4) shows the images after 1000 abrasion cycles. Clearly, the fabric for "P" style is less resistant to abrasion. All test cover all are approved for use with particulate and low toxicity pesticides that carry a 'Caution' label.

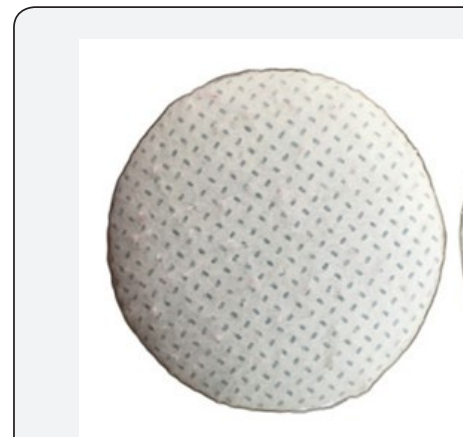

(a)

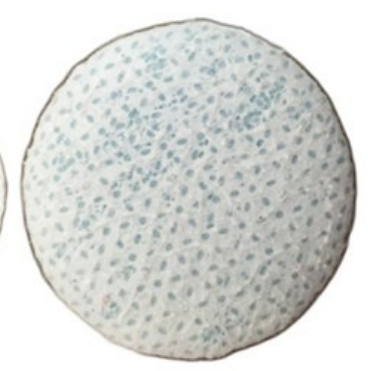

(b)
Figure 4: The wear performance of coveralls' fabrics; (a) the fabric for "B" and "R" style; (b) the fabric for"P" style.

\section{Wearer trial experiments}

To evaluate the effects of design features of the above three styles of coveralls on the ease of movement, fit and durability during routine wear, these three sets of coveralls were provided to agriculture workers in four states: California, Colorado, New York and Hawaii. Each cover all of these three styles was worn for 2 to 4 hours over a 2 week period under routine working conditions.

Written logs (provided) are made by the wearers. Dates and times worn, general environmental conditions, tasks, and whether the coveralls tore and how, as well as general comments on the fit and mobility of the cover all were recorded. After the 2 week period, the coveralls and logs were collected, and questionnaires about the performance of the coveralls were conducted.

\section{Results and Analysis}

\section{Distribution of wearers}

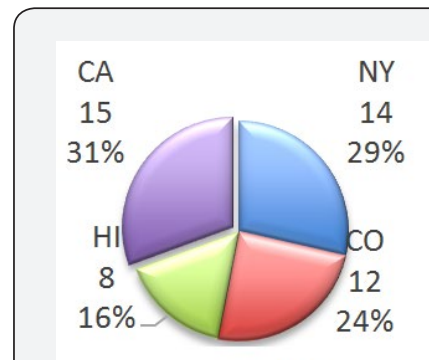

(a)

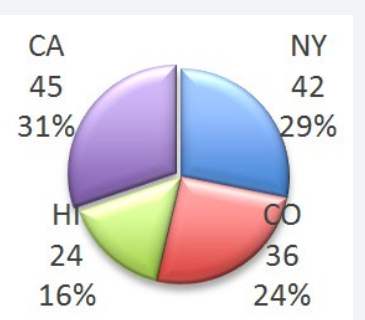

(b)
Figure 5: Distribution of wearers (a) and wearer trial records (b).

Totally 49wearers evaluated the coveralls. They were distributed in four states: 15 persons in California, 14persons in New York, 8 persons in Hawaii, and 12 persons in Colorado. Every person tried on each coverall of the three styles, so there were 147 records obtained. The distribution of the wearers and wearer trial records are shown in (Figure 5).

\section{Fitting}

Wearers chose to wear the size of best fit of the coveralls from the five sizes provided according to their body build. The distribution of sizes is shown in (Figure 6). Among the various sizes, Size L was the most commonly used, followed by size M and XL. 8 workers chose the size that was most suitable to them, but didn't record the size of the coveralls they wore.

\section{0}

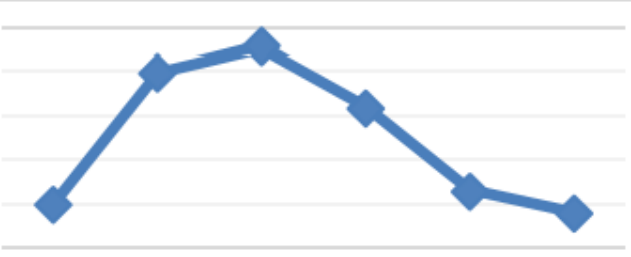

\section{$\begin{array}{llllll}S & M & L & X L & X X L & N A\end{array}$}

Figure 6: The using frequency of sizes.

Out of the 147 records, 62 recorded the degree of fit, which is shown in (Figure 7 (a)). 85\% responded that their coveralls provided good or moderate fit. Further analysis showed that "P" style had the most records of poor fit and the least records of good fit. In contrast, "R" style had the most records of good fit and the least records of poor fit. The results are plotted in (Figure 7 (a)). 13 records showed the "P" style was not acceptable while 9 records were for of " $\mathrm{B}$ " style and " $\mathrm{R}$ " style respectively, which is shown in (Figure 7 (b)).

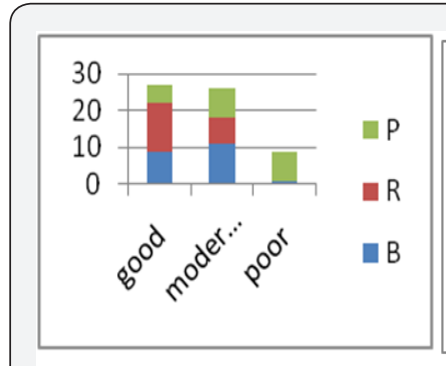

(a)

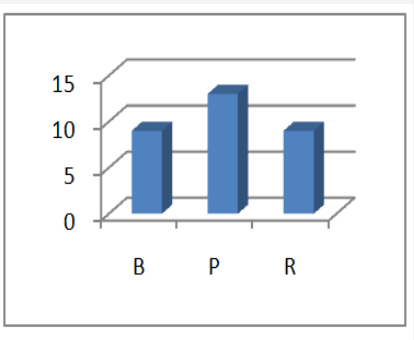

(b)
Figure 7: Fit of Different Coveralls. (a) responses on the degree of fit for three styles; (b) Number of unfitting cases for each style.

40 comments or suggestions were presented in altering the style of the coveralls for better fit. The common suggestion for three styles include adding pocket for cell phone or tools, removing ankle elastic and adding leg opening zippers for boots, using different color, using comfortable fabrics to avoid heat stress. But for the "P" style, 3 comments focused on the sang of pleats that can be expended but did not lie flat. 3 complained 
men's presented to the tightness sat the on shoulder area and another 3 complained the hindrance of the pleats as they did not lay flat and fully recover after stretching, . So we can think the even though the pleats of the "P" style do were intended to provide more mobility to the wearer as they raise the arms, bend over and raise their legs., but were perceived as a hindrance due to the fullness of the pleats.

\section{Durability and dirt stains}

Table 2: Rating of Worn Area in Terms of Tear, Abrasion and Dirt Stains.

\begin{tabular}{|c|c|c|c|c|c|}
\hline Worn scale & Very Small Area & Small Area & Medium Area & Large Area & Very Large Area \\
\hline Size of Worn Area (inches) & less than 1" & 1" to 2" & 2" to 3" & 3" to 5" & larger than 5" \\
\hline Rating of Worn Area & 1 & 2 & 3 & 4 & 5 \\
\hline
\end{tabular}

\section{Analysis of tear records}

Among the total of 147 records, there are 33 records with tears in different locations. The overall tear quantities, locations, and ratings are shown in (Figure 8).

It can be seen from (Figure 8 (a) \& (b)); the sleeve (wrist, elbow and arm) section has the least tear risk for three styles. The sections with high tear risk are different in three styles. "R" style as a whole has lowest tear risk. The relative higher tear risk sections occurred on torso and ankle, while "P" style has the highest tear risk in most of sections except sleeves section."B"style has higher tear risk in hip, ankle and knee sections.
The coveralls were worn in routine working conditions, and then were collected and a team of researchers inspected each coverall for detailed wear information (including tears, areas of abrasion and dirt stains)at different body locations including wrist, elbow, arm, shoulder, thigh, knee, lower leg, ankle, torso, and hip. To facilitate statistical analysis, the degree of wear was graded according to the size of the worn area as specified in (Table 2).

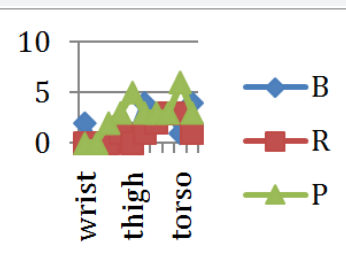

(a)

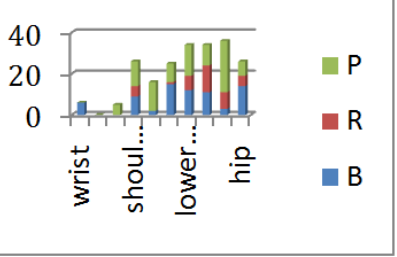

(b) different body parts. (a) Number of tears; (b) Aaccumulated tears ratings.
Figure 8: Number of tears and accumulated tear ratings in

Table 3: Results of Paired Samples T tests of Tearing Rating.

\begin{tabular}{|c|c|c|c|c|c|c|c|c|c|}
\hline & & \multicolumn{5}{|c|}{ Pair Difference } & \multirow{3}{*}{$\mathbf{T}$} & \multirow{3}{*}{ Df } & \multirow{3}{*}{ Sig. (2-tailed) } \\
\hline & & \multirow{2}{*}{ Mean } & \multirow{2}{*}{$\begin{array}{c}\text { Std } \\
\text { Deviation }\end{array}$} & \multirow{2}{*}{$\begin{array}{l}\text { Std. Error } \\
\text { Mean }\end{array}$} & $\begin{array}{c}\mathbf{9 5 \%} \text { Confidence Interval of } \\
\text { Difference }\end{array}$ & & & & \\
\hline & & & & & lower limit & upper limit & & & \\
\hline pair 1 & B - R & -1.646 & 5.353 & .773 & -3.200 & -.091 & -2.130 & 48 & .038 \\
\hline pair 2 & $B-P$ & -.510 & 4.088 & .584 & -1.684 & .664 & -.874 & 48 & .387 \\
\hline pair 3 & $R-P$ & -1.184 & 3.860 & .551 & -2.293 & -.075 & -2.146 & 48 & .037 \\
\hline
\end{tabular}

With regard to the number of tears, further analysis showed that some tears (8 records)were caused by stressed seams that form grin hole, and some ( 3 tears) appeared on the bottom zipper that might be caused by the sewing quality. There were 6 holes in the pleated areas of the cover all. It appeared that the pleated structure was not ideal in resisting tears.

Paired samples T test was used to determine the significance of the tear ratings between the three styles. The results are shown in (Table 3).

Thus it can be seen that " $R$ " style has a significantly different $(\mathrm{P}<0.05)$ tear performance from " $\mathrm{B}$ " style and " $\mathrm{P}$ " style. Furthermore, the mean tear rating of " $R$ " style is 0.80 , which is significantly less than that of the other two styles' mean abrasion rating, which is 1.47 for " $\mathrm{B}$ " and 1.98 for "R", respectively. As can be seen, the mean tear rating of " $\mathrm{R}$ " style was the lowest, indicating the " $\mathrm{R}$ "style was the best in resisting tear.

\section{Analysis of abrasion records}

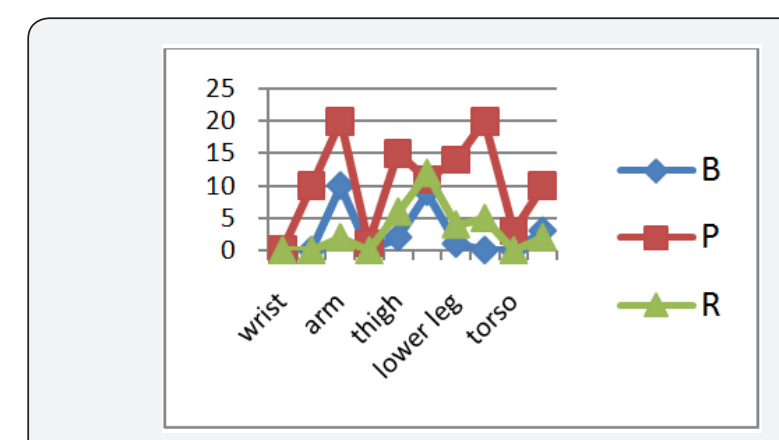

Figure 9: Abrasion ratings of three styles in different body parts. 
In (Figure 9), the accumulated abrasion ratings of the three styles in different body parts are presented. The mean abrasion rating of "P" style is 2.17 , which is significantly greater than that of the other two styles' mean abrasion rating, which is 0.52 for "B" and 0.65 for"R", respectively. As can be seen, the "P" style had the highest abrasion rating, indicating the worst performance in abrasion resistance. The "B" style has the lowest abrasion rating, indicating the best abrasion resistance.

Paired samples T tests were again carried out to analyze the significance of the differences between the three styles in terms of abrasion resistance. The results are shown in (Table 4).

Table 4: Results of paired samples $T$ tests of Abrasion Ratings.

\begin{tabular}{|c|c|c|c|c|c|c|c|c|c|}
\hline & & \multicolumn{5}{|c|}{ Pair Difference } & \multirow{3}{*}{$\mathbf{T}$} & \multirow{3}{*}{ df } & \multirow{3}{*}{ Sig. ((2-tailed $)$} \\
\hline & & \multirow{2}{*}{ Mean } & \multirow{2}{*}{ Std. Deviation } & \multirow{2}{*}{ Std. Error Mean } & \multicolumn{2}{|c|}{$\begin{array}{c}95 \% \text { Confidence Interval of } \\
\text { Difference }\end{array}$} & & & \\
\hline & & & & & Lower limit & Upper limit & & & \\
\hline pair 1 & B - P & -1.646 & 5.353 & .773 & -3.200 & -.091 & -2.130 & 48 & .038 \\
\hline pair 2 & $B-R$ & -.125 & 3.119 & .450 & -1.031 & .781 & -.278 & 48 & .782 \\
\hline pair 3 & P- R & 1.521 & 4.722 & .682 & .150 & 2.892 & 2.231 & 48 & .030 \\
\hline
\end{tabular}

Table 4 shows the "P" style had a significantly different abrasion performance $(\mathrm{P}<0.05)$ from

The "B" and "R" style. It should be noted that the fabric for the "P" style had much weaker abrasion resistance than that for "B" and "R" style. So, the poor abrasion performance of "P" style is the likely caused by the poor abrasion resistance of its fabric.

\section{Analysis of dirt stain records}

Among the total 147 records, there are 123 records with dirt stains in different body parts. That means dirt stains are hard to avoid. (Figures10 (a) and (b)) plot the accumulated number of dirt stains and dirt ratings in different body parts, respectively. A comparison of the numbers of the dirt stains of the three styles are shown in (Figure 10(c)).

From (Figure10 (a) and (b)), it can be seen that dirt stains were more frequent in the arm, thigh, lower leg and the torso areas. Further analysis shows the recorded count of dirt stains for "B" style is 43 , while both of that for "P" and "B" style are 40.As can be seen, the "B" style acquired the most dirt stains.

Paired samples T test was used to analyze the significance of the difference between the three styles in terms of dirt ratings. The results are listed in (Table 5).

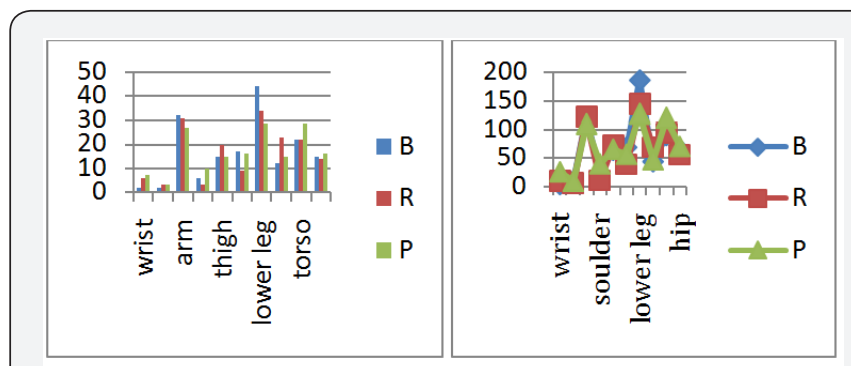

(a)

(b)

Figure 10: Analysis of dirt stains; (a) accumulated number of dirtstains in different body parts; (b)accumulated dirtratings in different body parts.

Table 5: Results of Paired Samples T Tests of Dirt Ratings.

\begin{tabular}{|c|c|c|c|c|c|c|c|c|c|}
\hline & & \multicolumn{5}{|c|}{ Pair Difference } & \multirow{3}{*}{$\mathbf{T}$} & \multirow{3}{*}{ DF } & \multirow{3}{*}{ Sig. $((2$-tailed $)$} \\
\hline & & \multirow[t]{2}{*}{ Mean } & \multirow[t]{2}{*}{ Std. Deviation } & \multirow[t]{2}{*}{ Std. Error Mean } & \multicolumn{2}{|c|}{$\begin{array}{c}95 \% \text { confidence interval of } \\
\text { difference }\end{array}$} & & & \\
\hline & & & & & Lower limit & Upper limit & & & \\
\hline pair 1 & B - R & 1.40816 & 8.11613 & 1.15945 & -.53649 & 3.35282 & 1.215 & 48 & .230 \\
\hline pair 2 & $B-P$ & -.12245 & 10.27868 & 1.46838 & -2.58526 & 2.34036 & -.083 & 48 & .934 \\
\hline pair 3 & $\mathrm{R}-\mathrm{P}$ & -1.53061 & 11.48024 & 1.64003 & -4.28132 & 1.22009 & -.933 & 48 & .355 \\
\hline
\end{tabular}

The results showed that the three coverall styles had no significant differences in preventing dirt stains. However, most dirt stains (7 dirt records) were reported in the pleated areas, indicating that the pleats might be prone to catch dirt.

\section{Discussion}

After analyzing the data of the relatively large scale wearer trials of three typical agricultural coverall styles, administered in four states, the following can be observed:

i. Based on the fit ratings and reports of the wearers, most of the coveralls had acceptable fit. The "R" style, which had elastic panels in the back, had the most records of good fit and the least records of poor fit, indicating the least complaints about its 
fit. It appears that the elastic panels are perceived as the most effective in providing adjustable fitting and help recover to the original shape after movement. On the contrary, the "P" style, which had pleats in body joint areas, had the worst results in fitting. From wearers' feedback, the pleats under the arm and in the buttock area are helpful to the movement, but the pleats at the knees were not perceived to have any effect. One problem with the pleats is that they are opened in stretch movements, but do not easily recover to their original shape. The pleats also make the coveralls bell away from the body, affecting the overall fit.

ii. With regard to the durability performance of the coveralls, the sleeve area has the least tear risk. The torso, ankle, lower leg and hip parts have relatively higher tear risk. Sewing processes should be carefully executed to prevent holes from forming at the seams or at the bottom of zippers. The pleated areas are also prone to tear damage, perhaps because these areas bell out from the body and are susceptible to snagging on equipment or other projections in the environment. The "R" style, which had elastic panels in the back, had the best tear resistance, probably related to its best performance in fit, as good fit reduces the tear force during body motion. In terms of abrasion performance, the "P" style performed the worst, probably due to the fact that the fabric for the "P" style had lower abrasion resistance, but it is also possible that the fullness of the pleated area exacerbated the abrasion between it and other garment parts during body motion. In terms of protection from dirt stains, no significant difference was found among the three styles. Nevertheless, it was observed that the pleated areas tended to catch and accumulate dirt due to its prominence.

iii. In Based on wearer feedbacks, the following improvements to the designs of coveralls were suggested: adding pockets, using larger zipper pulls, removing ankle elastic and adding leg opening zippers, using different color, using comfortable fabrics to avoid heat stress, and improving fit for different areas of the body (for example to accommodate a larger chest or proper proportion between torso and leg), etc.

iv. Although two different fabrics are used in the three styles due to practical constraints, our findings on the style comparison are still valid. This is because although the fabric for " $\mathrm{P}$ " style is softer, "P" style had most complaints in terms of fitting and mobility; although the fabric for "P" style has a higher tear strength, "P" style is more prone to tear.

\section{Conclusion}

Three styles of disposable agricultural coveralls were evaluated through wearer trials. These three styles are a traditional coverall from the marketplace (Labeled as "B"), a modified coverall of the same style with elastic panels under the arm and at in the back (Labeled as "R") and the new design with incorporated pleated sections (Labeled as "P"). Three styles of disposable agricultural coveralls were evaluated through wearer trials. These three styles are a traditional coverall from the marketplace (Labeled as "B"), a modified coverall of the same style with elastic panels in the back(Labeled as "R")and the new design with incorporated pleated sections (Labeled as "P"). By analyzing the data of the wearer trials and wearers' feedbacks, it was found that the pleat design in "P" style was the least preferred in terms of fitting as the pleats were opened in stretch movements and present a hindrance due to the fact that they did not lay flat. Instead, users preferred the "R" style as the elastic panels under the arms and at back provides adjustability for fitting. The "R" style also showed the least tear damage in high tear risk areas (i.e. torso, ankle and lower leg), while the "p" style has the higher tear risk in most of sections except the sleeve section. In terms of abrasion resistance, the " $\mathrm{B}$ " style is most preferred, followed by the " $\mathrm{R}$ " and "P" style. No significant differences were found among the three styles in terms of dirt resistance.

Analyzing the data of the wearer trials and wearer's feedbacks showed "P" style behaved the worst performance in fit, tear and abrasion. These results were partly affected by its fabric, partly affected by the pleats structure. While "R" style was the most preferred that showed best fit and durability properties among these three styles, No significant differences were found among the three styles in terms of dirt resistance. Furthermore, some feedback and suggestion of wearers can be used for the future improvement can be made by adding pockets, using larger zipper pulls, removing ankle elastic and adding leg opening zippers, and making adjustable fit at different areas of the body of cover all.

\section{Acknowledgement}

The authors would like to acknowledge the funding support of National Institute of Food and Agriculture (NIFA) through a Hatch/Multi State Project (Multistate Number: NC170; Project Number: NYC-329859) entitled "Development of Protective Clothing for Health and Agricultural Workers".

young female consumers' purchasing behaviors toward cool products, which then allows them to develop strategies to increase sales of new products targeted to young female consumers based on a more in-depth understanding of perceptions of cool. The findings offer guidance to apparel commercial marketers in determining which hedonic cool products are congruent with their targeted young female consumers' actual self-image.

\section{References}

1. Crow RM, Dewar MM (1986) Stresses in clothing as related to seam strength. Textile Research Journal 56(8): 467-473.

2. Airey DR (1990) Protective clothing: a manufacturer's viewpoint. Journal of Occupational Accidents (11): 269-275.

3. Ashdown SP, Watkins SM (1992) Movement analysis as the basis for the development and evaluation of a protective cover all design for asbestos abatement. In: Mc Briarty JP \& Henry NW (Eds.), Performance of protective clothing: ASTM STP 113, PA: ASTM, Philadelphia, USA, pp. 660-674. 
4. Huck J, Kim Y (1997) Coveralls for grass fire fighting. International Journal of Clothing Science and Technology 9(5): 346-359.

5. Huck J, Maganga O, Kim Y (1997) Protective overalls: evaluation of garments design and fit. International Journal of Clothing Science and Technology 9(1): 45-61.

6. Boorady LM, Haise C, Rucker M, Ashdown SP (2009) Protective clothing for pesticide applicators: a multi method needs assessment. Journal of Textile and Apparel Technology and Management 6(2): 1-17.

7. Boorady LM (2011) Functional Clothing-Principles of fit. Indian Journal of Fiber \& Textile Research 36: 344-347.

8. Jeon E, Moon J (2013) Size analysis on disposable protective covers all. Journal of the Korean Society of Clothing and Textiles 37(5): 655-666.

9. Holmer I, Nilsson H, Rissanen S, Hirata K, Smolander J (1992) Quantification of heat balance during work in three types of asbestosprotective clothing. Int Arch Occup Environ Health 64(4): 243-249.
10. Turpin LE, Meyer JP (2003) Comparison of physiological and subjective strain in workers wearing two different protective coveralls for asbestos abatement tasks. Appl Ergon 34(6): 551-556.

11. Turpin LE, Meyer JP (2007) Comparison of physiological and subjective strains of two protective coveralls in two short physically simulated tasks. Appl Ergon 38: 249-252.

12. Huck J, Maganga O, Kim Y (2007) Protective overalls: evaluation of garment design and fit. International Journal of Clothing Science and Technology 9(1): 45-61.

13. Reinertsen RE, Færevik H, Holbø K, Nesbakken R, Reitan J, et al. (2008) Optimizing the performance of phase-change materials in personal protective clothing systems. Int J Occup Saf Ergon 14(1): 43-53.

14.Workman JE, Lentz, ES (2000) Measurement specifications for manufacturers' prototype bodies. Clothing and Textiles Research Journal 18(4): 251-259.

\section{Your next submission with Juniper Publishers will reach you the below assets}

- Quality Editorial service

- Swift Peer Review

- Reprints availability

- E-prints Service

- Manuscript Podcast for convenient understanding

- Global attainment for your research

- Manuscript accessibility in different formats ( Pdf, E-pub, Full Text, Audio)

- Unceasing customer service

Track the below URL for one-step submission https://juniperpublishers.com/online-submission.php 